\title{
Vinorelbine-Epirubicin Regimen
}

National Cancer Institute

\section{Source}

National Cancer Institute. Vinorelbine-Epirubicin Regimen. NCI Thesaurus. Code C63434.

A regimen consisting of vinorelbine and epirubicin used for the treatment of metastatic breast cancer. 